Ärztliche Erfahrung beschränkt sich nicht auf medizinisches Fachwissen. Sie entsteht auch aus den mehr oder minder alltäglichen, heiter, ärgerlich oder nachdenklich stimmenden Erlebnissen mit Patienten, Kollegen und Mitarbeitern. Senden Sie uns Ihre Geschichte an: Brigitte.Moreano@springer.com. Für jeden veröffentlichten Text erhalten Sie bis zu 100 Euro.

\title{
Das Rezept gegen Rüpel
}

- Aggressive Menschen ertrotzen sich ja manchmal Rezepte, die wir eigentlich gar nicht schreiben wollen. So ein Rüpel hatte für seine Frau Krankengymnastik erpresst,

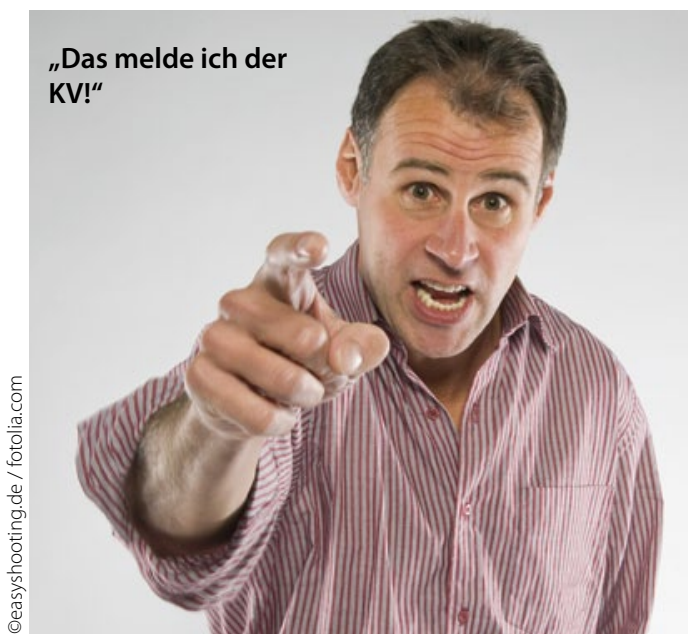

die sie auch schon mal in nette Massagen ummünzte. Ihr Apoplex war längst folgenlos ausgeheilt.

Als ich das erfuhr, war Schluss: „Ich schreibe das nicht mehr auf!" konstatierte ich. „Das müssen Sie aber!" entgegnete er scharf. "Muss ich nicht, weil nicht notwendig!" konterte ich. "Ich melde das der KV!" schrie er. "Gerne!" lächelte ich. "Dann erzähle ich überall herum, dass Sie keine Patienten mehr brauchen!" drohte er. "Keine wie Sie", dachte ich, aber sagte es nicht.

„Da unsere Chemie offensichtlich nicht stimmt, können Sie sich gern einen anderen Hausarzt suchen", bot ich an. "Sie lehnen unsere Behandlung ab?" japste er. "Nein, nur muss alles im Rahmen bleiben,

\section{Wer dumm fragt ...}

- Das „Unwort" des Jahres wird jedes Jahr gewählt. Für mich gibt es mittlerweile einen „Unsatz" oder besser eine „Unfrage" die sich so sehr verbietet und die man auf keinen Fall stellen darf, denn sie könnte ja jemanden diskriminieren und diese Frage lautet: "Wo kommen Sie denn her?"

Also lässt man sich was Schlaues einfallen und fragt um die Ecke, wie zum Beispiel: "Haben Sie Ihren Impfpass dabei?" Hier könnte ja etwas Aufschlussreiches drinstehen.
Das vorletzte Mal, als ich es unbedingt wissen wollte, saß ein bildschöner Student vor mir. Den konnte ich überhaupt nicht einordnen. Er kam aus Madagaskar (aber er hatte keine Pest, er brauchte nur ein Attest).

Letztens ist es mir bei einem Schwarzafrikaner doch blöderweise wieder rausgerutscht dieses dämliche "Wo kommen Sie denn her?" und prompt bekam ich zur Antwort: „Aus dem Alfred Messel Weg." Dort steht das Studentenheim ...

DR. MED. LUISE HESS, DARMSTADT . und man sollte sich doch irgendwie sympathisch sein, oder?“ fragte ich. „Das erzähle ich in der ganzen Stadt!" brüllte er erbost. „Die weiß ja, woher es kommt", murmelte ich, aber nur im Stillen. „Auf Wiedersehen, oder besser Adieu!" sagte ich laut.

Dr. med. Frauke Höllering, ARNSBerg *

\section{Fettnäpfchen}

— Es gibt Formulierungen, die mich selbst beim größten Stress zum Schmunzeln bringen. Dazu gehört etwa der berühmte Ausspruch des Sportreporters Heinz Mägerlein, der ein Skirennen einmal einleitete: „Sie standen an den Hängen und Pisten." Wie solche missverständliche Formulierungen entstehen, erlebte ich in meiner eigenen Praxis:

Ein Mann von ca. 50 Jahren kam in die Sprechstunde, in seinem Schlepptau eine ältere, kleine, schmächtige Dame. An der Theke angekommen sagte er zur Helferin: „Ich hätte gern ein Rezept für ein Medikament für meine Mutter."

Daraufhin erwiderte unsere Arzthelferin: „Haben Sie die alte Schachtel dabei?" Leicht irritiert drehte sich der Mann zu seiner Mutter um ...

DR. med. Jürgen RABE, DReieich • 